\title{
An Integrated Framework for the Performance Evaluation of Fruits and Vegetable Store Located in a Supermarket
}

\author{
Susovan Jana ${ }^{1, *}$, Bijan Sarkar ${ }^{1}$ and Ranjan Parekh² \\ ${ }^{I}$ Department of Production Engineering, Jadavpur University, Kolkata, India \\ ${ }^{2}$ School of Education Technology, Jadavpur University, Kolkata, India
}

('Corresponding author's e-mail: jana.susovan2@gmail.com)

Received: 29 August 2020, Revised: 2 May 2021, Accepted: 29 May 2021

\begin{abstract}
The quality of fruits and vegetable stores should be maintained with high priority for customer satisfaction. The performance evaluation of fruits and vegetable store located in a supermarket is a big challenge for the managerial personnel of the supermarket. In this paper, a new performance evaluation framework is proposed for the fruits and vegetable store located in a supermarket. The criteria for performance evaluation have been found out in a hierarchical structure through a brainstorming session among the experts. The 4 top-level criteria are storage, processing, sales and transport. These 4 top-level criteria are broken into 9 lower-level criteria. Fuzzy AHP is used to calculate the weights of criteria for each level of the hierarchy. Fuzzy TOPSIS generally ranks the alternatives. An improved fuzzy TOPSIS, which is named fuzzy k-TOPSIS, is proposed here to find out the rank as well as classification of the stores of fruits and vegetables. The proposed framework is demonstrated here with a case study for a better understanding of the complete framework.
\end{abstract}

Keywords: Fruits, Vegetables, MCDM, Fuzzy AHP, Fuzzy TOPSIS, k-means clustering

\section{Introduction}

Food is one of the physiological needs of human beings as shown in Maslow's hierarchy of needs [1]. A large number of fruits and vegetables [2] are consumed daily by humans. Consumable fruits and vegetables have to pass many stages before they reach the end customer. The safety and quality of the products are the major concern for the food processing industry in today's world. There was a meat scandal in Kolkata and nearby places in West Bengal, India in May 2018. Some reputed restaurants were caught on selling moldy meat to the customers. This kind of incident spreads threats very quickly in our society. The safety issue of food is not limited to local or any geographical region. It becomes a global issue. In 2014, the OSI group was also involved in a food scandal [3] in China. A television channel accused them of extending the expiry date of meat illegally.

Nowadays, there is a trend of buying fruits and vegetables from the store located in a supermarket. Customers are getting fresh fruits and vegetables in supermarkets like an open market. They are very much concerned about the freshness of fruits and vegetables [4] as well as the safety of health. Figure 1 depicts that the goal of the customer from all the directions is to get fresh and safe fruits and vegetables as if all road leads to ROME. People always search for a good store for buying fruits and vegetables. Many criteria may impact the choice of the store containing fruits and vegetables. The need is to find a suitable path to reach the goal of fresh and safe fruits and vegetables. Hence, a performance evaluation framework is proposed here considering all the criteria affecting the performance of the store from all sides. In this proposed framework, Multi-criteria Decision Making (MCDM) and data mining approaches are combined to determine the performance-based classification of fruits and vegetable stores located in different supermarkets. The decision-makers give their input in linguistic terms. This framework adopted MCDM techniques for the fuzzy environment to handle linguistic inputs. The weights of criteria are calculated by using the Analytic Hierarchy Process (AHP), from the pairwise comparison matrix, which is formed with a relative score given by the experts. Generally, the Technique for Order of Preference by Similarity to Ideal Solution (TOPSIS) is used by the authors to rank the alternative stores from the decision matrix, which is formed with the rating from the experts. But, only the ranking of the alternative fruits and vegetable stores may not be enough when the number of alternatives is large. The classification 
or categorization based on performance is needed in that case. k-TOPSIS technique is introduced to generate the ranking as well as the classification among the alternative stores of fruits and vegetables. The k-means clustering, an unsupervised clustering technique is blended with the TOPSIS to do the classification.

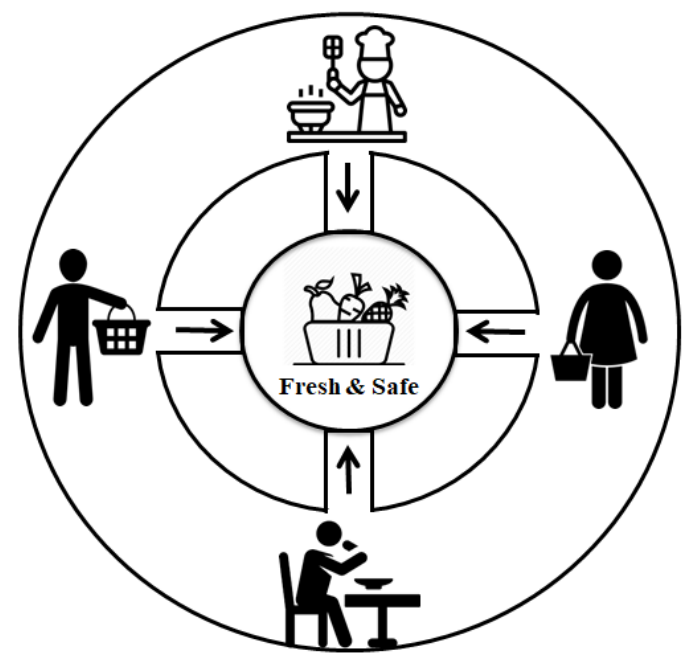

Figure 1 The goal of the customers for buying fruits and vegetables.

\section{Literature review}

The performance evaluation of fruits and vegetable stores is a multi-criteria decision-making problem. A good number of papers were published to address different challenges in the food industries as well as in the agricultural sector. This literature review mostly considered those papers with a solution using MCDM techniques. Wang et al. [5] proposed a food safety evaluation technique for food supply chain management using AHP and TOPSIS. They have identified 5 target areas to make 18 indices for the evaluation. The target areas are procurement, storage, transport, processing, and sales. The AHP is used to generate the weights of criteria. The TOPSIS is used to create the rank of alternatives. The proposed framework will identify the best supermarket with respect to food safety as well as helps the managerial persons in other supermarkets to identify their flaws. Duman et al. [6] also proposed a performance evaluation approach of food industries by analyzing the qualitative and quantitative data. The identified qualitative criteria are product quality, food safety, operational safety and store image. The service preference was considered as quantitative data. In the first stage, AHP computes the weights for the criteria. The data envelopment analysis (DEA) with a cross-efficiency measure was used to obtain the efficiency score of quantitative data of service performance. Finally, TOPSIS was used to evaluate the overall rank of food stores. Raut et al. [7] identified 16 causes of post-harvest fruits and vegetable losses from the Indian perspective. The reasons include lack of storage, poor infrastructure, climate, linkage gaps between stakeholders, etc. The authors applied AHP to estimate the global weights of the criteria and rank them based on the weights. This approach has some limitations also. The judgment of weight is very crucial and it more dependent on the technical knowledge of the decision-makers. Raut et al. [8] proposed a different approach for the evaluation of cold-third party logistics providers (CTPLs). The approach aims to reduce the post-harvest losses in the fruits and vegetables supply chain. The authors identified 5 criteria as well as thirty sub-criteria for the evaluation of CTPLs. The fuzzy DEMATEL was applied to explore the cause-effect relationship and rank the criteria. The fuzzy AHP was applied to compute the weights of criteria and evaluation of CTPLs. The proposed approach has some managerial prospects to identify the reasons for food losses and taking initiatives to reduce the loss of perishable food items.

Different multi-criteria decision-making tools are applied in different problem areas i.e AHP [9], TOPSIS [10], Complex Proportional Assessment with Grey Relations (COPRAS-G) [11], and Multiobjective Optimization on the Basis of Ratio Analysis (MOORA) [12], etc. The AHP and TOPSIS have been applied enormously to address MCDM problems in different sectors. An exhaustive survey is also done on the state-of-the-art application of AHP, TOPSIS. The combination of these 2 techniques is used 
for different problems across different sectors. The techniques addressed the problems like supplier selection in the steel industry [13], evaluation of energy development plants [14], the health sector $[15,16]$, evaluation in banking [17], human resource and project management [18,19], and transport $[20,21]$. The advantages of using AHP-TOPSIS over other MCDM techniques are geometric meaning, less computation overhead, less distortion of information, distance-based ranking methodology.

\section{Background research}

The proposed framework is an integrated approach of fuzzy set theory, AHP, TOPSIS, k-means clustering. The current section contains background research on the said topics.

\section{Fuzzy set theory}

Fuzzy sets were first introduced by Zadeh [22], a professor of UC Berkeley in California in 1965. Fuzzy logic offers better and realistic decisions considering uncertainty. If the universe of discourse is $X$ then a fuzzy set $\tilde{A}$ is defined with a membership function $\mu_{\tilde{A}}(x)$. Refer to Eq. (1). The value of a membership function should be between 0 and 1 . Here, we are considering only the triangular membership function. Refer to Eq. (2). It can be defined with a triplet of $\{a, b, c\}$.

$A=\left\{\left(x, \mu_{A}(x)\right) \mid x \in X\right\}$

$\mu_{\tilde{A}}(x)=\left\{\begin{array}{cc}0 & \text { if } x \leq a \\ \frac{x-a}{b-a} & \text { if } a \leq x \leq b \\ \frac{c-x}{c-b} & \text { if } b \leq x \leq c \\ 0 & \text { if } c \leq x\end{array}\right.$

\section{Linguistic terms and fuzzy numbers}

The linguistic terms are used by the experts for relative importance as well as rating. Table 1 shows the linguistic terms used for relative importance and corresponding triangular fuzzy number. It also shows the mapping of linguistic terms and the real number used by Saaty in AHP. Table 2 shows the mapping of linguistic ratings and corresponding triangular fuzzy numbers.

Table 1 The fuzzy scale of the relative importance.

\begin{tabular}{cccc}
\hline Linguistic terms & Abbreviation & Saaty's scale & Fuzzy numbers \\
\hline Equal & EQ & 1 & $(1,1,1)$ \\
\hline Moderate & MO & 3 & $(2,3,4)$ \\
\hline Strong & ST & 5 & $(4,5,6)$ \\
\hline Very strong & VS & 7 & $(6,7,8)$ \\
\hline Extremely strong & ES & 9 & $(1,2,3)$ \\
\hline Intermediate values & & 2 & $(3,4,5)$ \\
\cline { 2 - 4 } & IV & 4 & $(5,6,7)$ \\
\cline { 2 - 4 } & & 6 & $(7,8,9)$ \\
\hline
\end{tabular}

Table 2 Mapping among linguistic terms and fuzzy numbers for the performance rating.

\begin{tabular}{ccc}
\hline Linguistic terms & Abbreviation & Fuzzy numbers \\
\hline Very low & VL & $(1,1,3)$ \\
Low & L & $(1,3,5)$ \\
Average & A & $(3,5,7)$ \\
High & H & $(5,7,9)$ \\
Very high & VH & $(7,9,9)$ \\
\hline
\end{tabular}




\section{Some operations on fuzzy numbers}

Assuming, 2 fuzzy numbers are $\widetilde{r}=\left(r_{a}, r_{b}, r_{c}\right)$, and $\tilde{s}=\left(s_{a}, s_{b}, s_{c}\right)$. The basic fuzzy operations are described below;

Addition between $\tilde{r}$ and $\tilde{s}$

$\tilde{r} \oplus \tilde{s}=\left(r_{a}+s_{a}, r_{b}+s_{b}, r_{c}+s_{c}\right)$

Multiplication of $\tilde{r}$ with a real number $(t)$

$t \otimes \tilde{r}=\left(t r_{a}, t r_{b}, t r_{c}\right)$, where $t \geq 0$ and $t \in R$

Division of $\tilde{r}$ with a real number $(t)$

$\tilde{r} \div t=\left(\frac{r_{a}}{t}, \frac{r_{b}}{t}, \frac{r_{c}}{t}\right)$, where $t \geq 0$ and $t \in R$

Reciprocal of $\tilde{r}$

$\tilde{r}^{-1}=\left(\frac{1}{r_{c}}, \frac{1}{r_{b}}, \frac{1}{r_{a}}\right)$

Distance between $\tilde{r}$ and $\tilde{S}$

$d(\tilde{r}, \tilde{s})=\sqrt{\frac{1}{3}\left[\left(r_{a}-s_{a}\right)^{2}+\left(r_{b}-s_{b}\right)^{2}+\left(r_{c}-s_{c}\right)^{2}\right]}$

\section{Fuzzy AHP}

The AHP, which is a powerful tool in the context of decision making, was first proposed by Saaty [23]. This technique is frequently applied to calculate the weights of criteria for MCDM problems. The detailed process is described below;

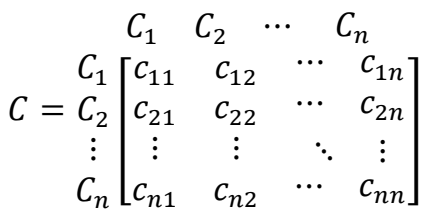

Step1: Construct a pairwise comparison matrix $(C)$ among the $n$ number of criteria using the linguistic terms mentioned in Table 1. Refer to Eq. (8).

Step 2: Each element of this pairwise comparison matrix will be converted to a fuzzy number using Table 1. Refer to Eqs. (9) - (10), where $i, j=1,2,3, \cdots, n$.

$\tilde{c}_{i j}=(l, m, u)$

$\frac{1}{\tilde{c}_{i j}}=\left(\tilde{c}_{i j}\right)^{-1}=\left(\frac{1}{u}, \frac{1}{m}, \frac{1}{l}\right)$

Step 3: Now, Buckley's geometric mean [24] based row-wise weight calculation is used here for each criterion. Refer to the Eqs. (11) - (12).

$\tilde{C}_{1} \otimes \tilde{C}_{2} \otimes \cdots \otimes \tilde{C}_{n}=\left(l_{1}, m_{1}, u_{1}\right) \otimes\left(l_{2}, m_{2}, u_{2}\right) \otimes \cdots \otimes\left(l_{n}, m_{n}, u_{n}\right)=\left(l_{1} * l_{2} * \cdots * l_{n}, m_{1} * m_{2} *\right.$ $\left.\cdots * m_{n}, u_{1} * u_{2} * \cdots * u_{n}\right)$

(11)

$\tilde{G}_{i}=\left(\left(l_{1} * l_{2} * \cdots * l_{n}\right)^{\frac{1}{n}},\left(m_{1} * m_{2} * \cdots * m_{n}\right)^{\frac{1}{n}},\left(u_{1} * u_{2} * \cdots * u_{n}\right)^{\frac{1}{n}}\right)$ 
Step 4: The fuzzy weight for each criterion is calculated using Eq. (13).

$\widetilde{W_{l}}=\tilde{G}_{i} \otimes\left(\tilde{G}_{1} \oplus \tilde{G}_{2} \oplus \cdots \oplus \tilde{G}_{n}\right)^{-1}$

Step 5: The triangular fuzzy weight $\widetilde{w}_{i}$ has 3 components i.e. $l_{i}, m_{i}$, and $u_{i}$. If there are $K$ numbers of decision-makers then aggregate weight can be calculated by using a fuzzy aggregation technique (AT) [25] to combine $K$ number of fuzzy weights. Refer to Eqs. (14) - (16).

$l_{i}=\min _{k}\left(l_{i}^{k}\right)$

$m_{i}=\frac{1}{K} \sum_{k=1}^{K} m_{i}^{k}$

$u_{i}=\max _{k}\left(u_{i}^{k}\right)$

Step 6: To get the crisp weights the center of area (COA) method is used for de-fuzzification. Refer to Eq. (17).

$w_{i}=\left(\frac{l_{i}+m_{i}+u_{i}}{3}\right)$

Step 7: Finally, the weights are normalized using Eq. (18).

$w_{i}=\frac{w_{i}}{\sum_{i=1}^{n} w_{i}}$

\section{Fuzzy TOPSIS}

The TOPSIS was first introduced by Hwang and Yoon [26]. It was further modified by Yoon [27]. The main idea behind this technique is that the selected alternative should have a minimum distance from the positive ideal solution (PIS) and the maximum distance from the negative ideal solution (NIS). The steps of fuzzy TOPSIS [28] are described below;

Step1: Let's assume that there is $m$ number of alternatives and $n$ number of criteria in the fuzzy decision matrix $(D)$. Each element in $D$ is $d_{i j}$, which represents the rating value of $i^{\text {th }}$ alternative for $j^{\text {th }}$ criteria in linguistic terms. Refer to Eq. (19).

$C_{1}$
$A_{1}$
$A_{2}$
$\vdots$
$A_{m}$$\left[\begin{array}{cccc}d_{11} & d_{12} & \cdots & C_{n} \\ d_{21} & d_{22} & \cdots & d_{1 n} \\ \vdots & \vdots & \ddots & \vdots \\ d_{m 1} & d_{m 2} & \cdots & d_{m n}\end{array}\right]$

Step 2: The linguistic rating is converted into a fuzzy number using the mappings in Table 2.

Step 3: The triangular fuzzy rating $\widetilde{\mathrm{d}}_{\mathrm{ij}}$ has 3 components i.e. $\mathrm{a}_{\mathrm{ij}}, \mathrm{b}_{\mathrm{ij}}$, and $\mathrm{c}_{\mathrm{ij}}$. An aggregate rating will be calculated by combing the rating from $\mathrm{K}$ numbers of decision-makers using the aggregation technique mentioned in 'Step 5' of fuzzy AHP.

Step 4: Benefit and cost criteria will be normalized using Eqs. (20) - (21), respectively. The final fuzzy normalized matrix will be $R=\left(r_{i j}\right)_{m \times n}$.

$\tilde{r}_{i j}=\left(\frac{a_{i j}}{c_{j}^{+}}, \frac{b_{i j}}{c_{j}^{+}}, \frac{c_{i j}}{c_{j}^{+}}\right)$, where $c_{j}^{+}=\max _{i}\left\{c_{i j}\right\}$

$\tilde{r}_{i j}=\left(\frac{a_{j}^{-}}{c_{i j}}, \frac{a_{j}^{-}}{b_{i j}}, \frac{a_{j}^{-}}{a_{i j}}\right)$, where $a_{j}^{-}=\min _{i}\left\{a_{i j}\right\}$

Step 5: The fuzzy weighted normalized decision matrix $S=\left(\tilde{S}_{i j}\right)_{m \times n}$ is computed using Eq. (22).

$\tilde{s}_{i j}=w_{i} * \tilde{r}_{i j}$ 
Step 6: Fuzzy Positive Ideal Solution (FPIS) and Fuzzy Negative Ideal Solution (FNIS) are identified using Eqs. (23) - (24), respectively.

$A^{+}=\left(\tilde{s}_{1}^{+}, \tilde{s}_{2}^{+}, \cdots, \tilde{s}_{n}^{+}\right)$, where $\tilde{s}_{j}^{+}=\max _{i}\left\{s_{i j 3}\right\}$

$A^{-}=\left(\tilde{s}_{1}^{-}, \tilde{s}_{2}^{-}, \cdots, \tilde{s}_{n}^{-}\right)$, where $\tilde{s}_{j}^{-}=\min _{i}\left\{s_{i j 1}\right\}$

Step 7: The distance $\left(E_{i}^{+}\right)$between each alternative and fuzzy positive ideal solution is computed using Eq. (25). Another distance $\left(E_{i}^{-}\right)$between each alternative and fuzzy negative ideal solution is computed using Eq. (26).

$E_{i}^{+}=\sum_{j=1}^{n} d\left(\tilde{s}_{i j}, \tilde{s}_{j}^{+}\right)$

$E_{i}^{-}=\sum_{j=1}^{n} d\left(\tilde{s}_{i j}, \tilde{s}_{j}^{-}\right)$

Step 8: In this step, the closeness coefficient is computed for each alternatives using Eq. (27).

$C C_{i}=\frac{E_{i}^{-}}{E_{i}{ }^{+}+E_{i}}$

Step 9: The rank of the alternatives is given based on the descending order of the closeness coefficient.

\section{k-means clustering}

k-means clustering, which is an unsupervised machine learning technique, is used to cluster the unlabeled data. MacQueen [29] used the term "k-means". The idea was the brainchild of Steinhaus [30]. The details of this algorithm are described below.

Input: Closeness coefficients $\left\{C C_{1}, C C_{2}, \cdots, C C_{m}\right\}$, number of classes

Output: Classification of alternatives among the desired number of classes.

Step 1: Select arbitrary cluster center $\left\{c_{1}, c_{2}, \cdots, c_{k}\right\}$ for each cluster.

Step 2: Calculate the Euclidean distance between data points and each cluster center using Eq. (28).

$d\left(C C_{i}, c_{k}\right)=\sqrt{\left(C C_{i}-c_{k}\right)^{2}}$

Step 3: Assign the data point to the particular cluster, from which the distance is minimum.

Step 4: Recalculate the new cluster centers using Eq. (29), where $P_{K}$ represents the number of data points in $k^{\text {th }}$ cluster.

$c_{k}=\left(\frac{1}{P_{k}}\right) \sum_{k=1}^{P_{k}} C C_{k}$

Step 5: Again, calculate the Euclidean distance between data points and the new cluster centers using Eq. (28).

Step 6: The iteration will stop if no data point needs reassignment otherwise repeats from step 3.

\section{Proposed framework}

The performance evaluation of stores for fruits and vegetables is an urgent need of the marketplace. In this paper, a new framework is proposed for ranking as well as classification among the stores for fruits and vegetables in different supermarkets. This framework contains 3 different phases. Figure 2 shows the complete architecture of the proposed framework.

Phase I: At first, an expert's committee is formed to analyze the problem. There will be a brainstorming session with the expert's committee. The outcomes of this session are criteria and subcriteria for decision making, as well as the selected alternatives for evaluation. Table $\mathbf{3}$ depicts the details of the experts selected in the committee. The selected committee members cover a good range of gender, ages, qualifications, experience as well as areas of expertise. The experts are living in crescendo. They are getting more and more knowledge from different sources like journals, conferences, lectures, etc. 
Phase II: In this phase, a fuzzy pairwise comparison matrix is formed with the relative importance score from experts. The relative importance was given in linguistic terms as mentioned in Table 1. The weights of the criteria will be calculated by using the fuzzy AHP technique from this pairwise comparison matrix.

Phase III: A fuzzy decision matrix is formed with the rating from experts. The linguistic ratings are given by following Table 2 . The performance evaluation is always made by the evaluator through both explicit knowledge as well as tacit knowledge which is comparable with the tip of the iceberg. The decision matrix will be normalized using separate techniques for benefit and cost criteria. Finally, the supermarkets are ranked and classified using the proposed fuzzy $k$-TOPSIS method. The ranking is not enough for evaluating a large number of supermarkets in a state or a country. The classification or categorization of supermarkets is needed based on performance. An unsupervised machine learning technique is used to classify supermarkets based on performance evaluation criteria. The classification is done by applying k-means clustering on the closeness coefficient, which is computed by fuzzy TOPSIS. The supermarkets are classified into 3 categories i.e. Class A, Class B and Class C.

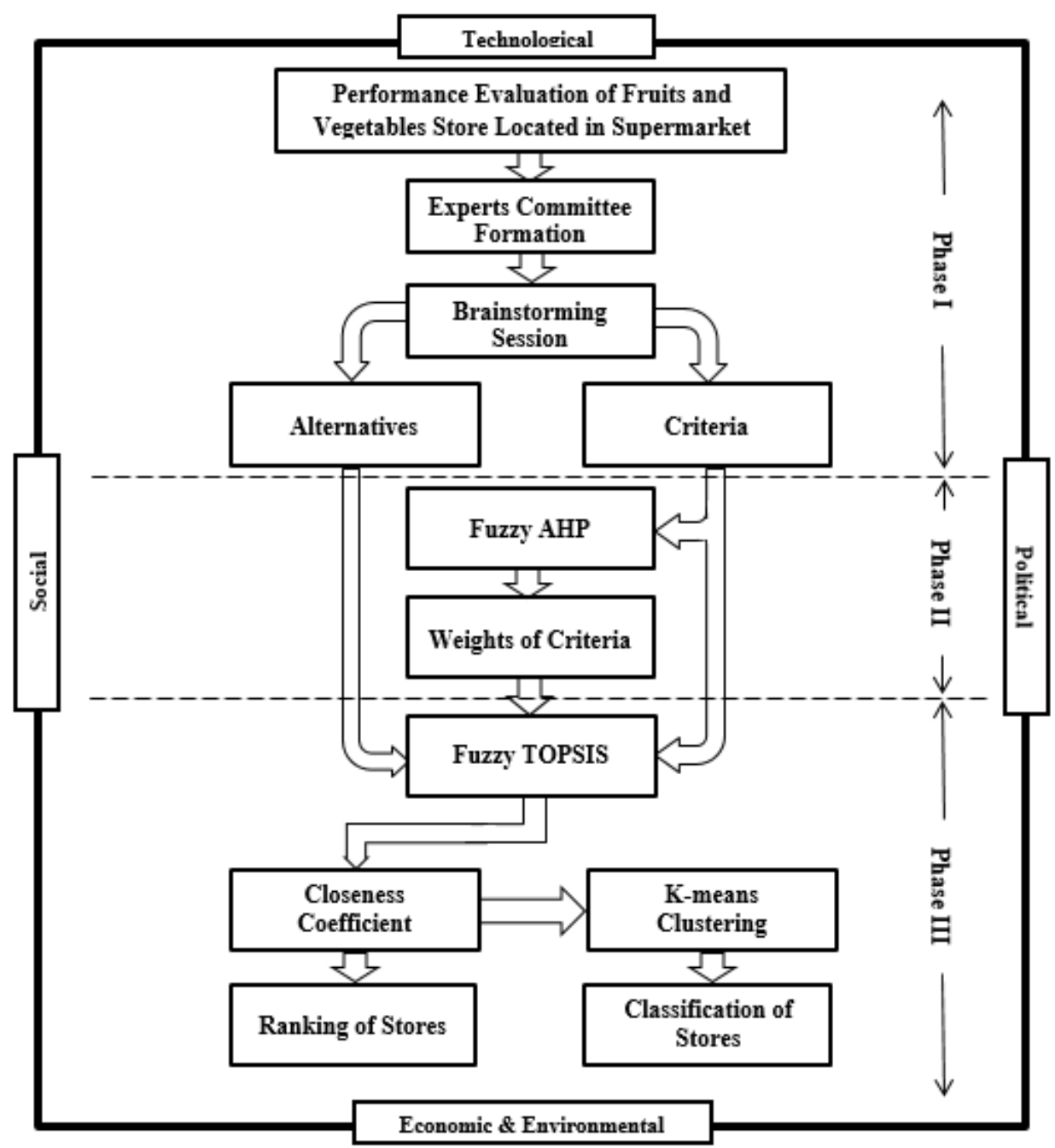

Figure 2 The complete architecture of the proposed framework. 
Table 3 The overall range of experts for this framework (explicit knowledge).

\begin{tabular}{|c|c|c|c|}
\hline Experts & E1 & $\mathbf{E 2}$ & E3 \\
\hline Gender & Male & Female & Male \\
\hline Age & 35 Years & 47 Years & 62 Years \\
\hline Qualification & $\mathrm{BE}$ & $\mathrm{ME}$ & Ph.D. \\
\hline Experience & 12 Years & 22 Years & 32 Years \\
\hline Area of expertise & Store management & $\begin{array}{c}\text { Finance \& strategic } \\
\text { planning }\end{array}$ & Quality management \\
\hline
\end{tabular}

The framework is protected by the political, economic, environmental, social, and technological (PEEST) forces, which makes a big impact on a business organization like a supermarket. Political laws, stability, and capability affect the state of business in any country. There are chances of occurring uncertain events due to an environmental cause like weather, climate, location, building position, etc. Financial stability plays a major role in the success of any business organization. The growth of a business depends on the population analysis of society. Also, there are technical risks with power, transportation, etc. This framework reduces the chances of occurring uncertain events and threats by PEEST analysis.

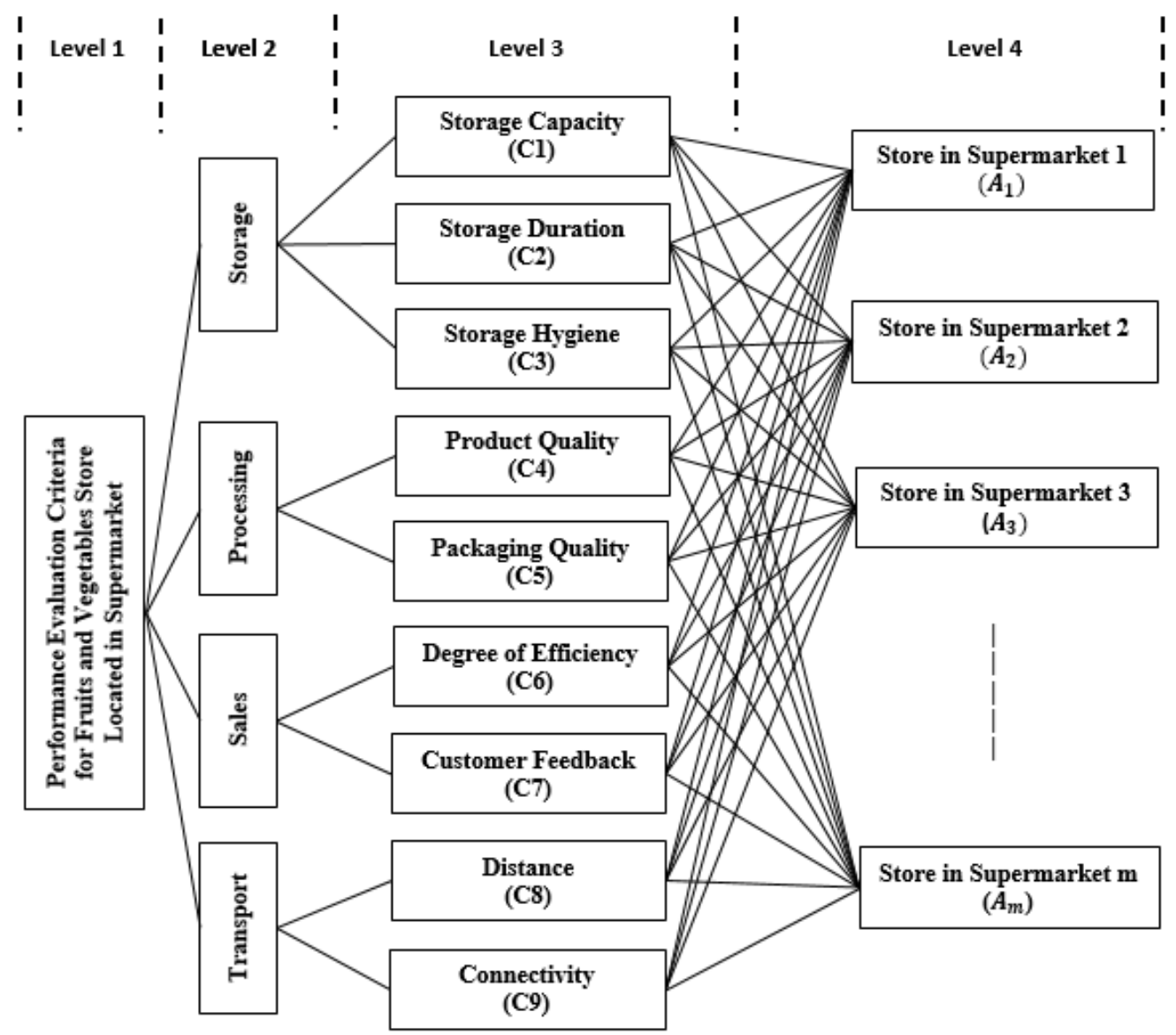

Figure 3 Hierarchy of the criteria. 


\section{Identification of criteria}

Several criteria affect the performance of the store containing fruits and vegetables. Three levels of criteria are identified here. Figure 3 shows the hierarchy of the criteria. In level 2, the experts have identified 4 major types of criteria, i.e. storage, processing, sales, and transport. These 4 criteria are the pillars of this decision-making framework for a fruits and vegetable store. All these top-level criteria are further subdivided into multiple criteria.

The storage criterion is sub dived into 3 criteria i.e. storage capacity $(\mathrm{C} 1)$, storage duration $(\mathrm{C} 2)$, and storage hygiene (C3). The storage capacity is the measure of the amount and variations of products available in the store. The store, which contains a variety of fruits and vegetables in large quantities, is always preferred by the customer. The storage duration indicates the amount of time that the fruits and vegetables stay in the store. The fruits and vegetable, which stays more time, are less fresh. Proper demand forecasting and appropriate order may lead to a faster flow of products in the store. The hygienic condition of the store is determined by the Storage Hygiene criterion. Storage hygiene has a direct impact on food safety.

The processing criterion is subdivided into 2 criteria i.e. product quality (C4), and packaging quality (C5). Good quality products will always remain on top of the priority list at the time of performance evaluation of the store. The quality of fruits and vegetables is determined by the shape, size, volume, weight, color, maturity, etc. The packaging condition makes the customer satisfied and also preserves the quality of fruits or vegetables inside the package.

The Sales criterion is also subdivided into 2 criteria i.e. degree of efficiency (C6), and customer feedback (C7). The degree of efficiency and behavior of the salesperson directly impacts the customer's mind. The humble behavior always attracts the customers. One of the most important criteria is customer feedback. The positive feedback always increases the popularity of the store. The negative feedback also helps the management to enhance the overall performance by improving the service.

The transport criterion has 2 sub-criteria i.e. distance (C8) and connectivity (C9). The distance of the store is a very important criterion. Fruits and vegetables come under the daily need of humans. Hence, the minimum distance between the store and locality is always preferred by the people. The connectivity is complimentary if the distance is high. The connectivity of the store location should be good if it is far from the locality otherwise it will be disliked by the customer for poor connectivity.

In total, there are 9 criteria in level 3. Those 9 criteria should be grouped into benefit criteria and cost criteria. The significance of this grouping is that there are different ways to normalize the fuzzy decision matrix for benefit criteria and cost criteria. The type can be easily identifiable. The value or rating for benefit criteria is higher the better. The reverse is true for cost criteria. That means the value or rating for cost criteria is lower the better. The benefit criteria are storage capacity $(+)$, storage hygiene $(+)$, product quality $(+)$, packaging quality $(+)$, degree of efficiency $(+)$, customer feedback $(+)$, and connectivity $(+)$. The cost criteria are storage duration $(-)$, and distance $(-)$.

\section{A case study}

The proposed framework is demonstrated here with an illustrative example. There are 3 experts in this committee. The experts are named E1, E2 and E3. The experts formed the pairwise comparison matrix at each level for the weight calculation of criteria. The top-level criteria affecting the performance of stores for fruits and vegetables are storage, processing, sales, and transport. There are still many criteria that could affect performance evaluation directly or indirectly. Table 4 shows the weights of specific criteria that are computed by fuzzy AHP. Equal priority has been given to each of the expert's opinions for calculating the aggregate weight of the criteria. A very popular aggregation technique is used here for triangular fuzzy numbers. The global weights are computed by multiplying the normalized weights in level 3 with the corresponding normalized weight in level 2 . The descending order of criteria as per the normalized global weights are product quality (C4), storage hygiene (C3), connectivity (C9), distance (C8), customer feedback (C7), packaging quality (C5), storage duration (C2), degree of efficiency (C6), and storage capacity (C1). The experts gave more emphasis on product quality and storage hygiene criteria which have a direct impact on the performance of the store. Those criteria affect a lot in safety and quality issues of the store of perishable items like fruits and vegetables. The moderate emphasis is given on connectivity and distance of the location. The fuzzy AHP calculates weights based on relative importance among the criteria. This is the reason that fuzzy AHP is preferred here over other weight calculation techniques. The weights of each criterion will help the fuzzy TOPSIS on decision making. 
The expert's committee has selected 24 fruits and vegetable stores for evaluation. The alternative stores are marked as A1, A2, A3, ...., A24. The experts have given ratings for particular criteria of particular stores by doing some questionnaires to the managerial person and customer of the supermarket. Table 5 shows the aggregate fuzzy rating of 3 experts using 'Step 3' of fuzzy TOPSIS. Table 6 lists the distance from FPIS $\left(E^{+}\right)$, distance from FNIS $\left(E^{-}\right)$, and closeness coefficient $(C C)$ value for each alternative using 'Step 7' and 'Step 8' of fuzzy TOPSIS. The final result of fuzzy TOPSIS is the rank among the alternatives. The aim of this work is the classification or categorization of stores along with ranks. This is not possible from ranking if the number of stores is very high. The performance-based classification is possible after applying k-means clustering on the closeness coefficient values. Table 6 also shows the final ranking of fruits and vegetable stores using the final step of fuzzy TOPSIS as well as classification results after applying k-means clustering on the closeness coefficient. The ranking of cluster i.e. "Class A", "Class B", \& "Class C" is done based on the value of cluster center in descending order. That means the stores that belong to "Class A" are better than the stores that belong to "Class B" and the stores that belong to "Class B" are better than the stores that belong to "Class C". In, this case study, the number of "Class A" stores is 8 . "Class B" and "Class C" get 14 and 2 stores, respectively.

Table 4 Criteria and corresponding weights using fuzzy AHP.

\begin{tabular}{|c|c|c|c|c|c|c|}
\hline \multicolumn{3}{|c|}{ Level 2} & \multicolumn{3}{|c|}{ Level 3} & \multirow{2}{*}{$\begin{array}{c}\text { Global } \\
\text { weights }\end{array}$} \\
\hline Criteria & Weights & $\begin{array}{l}\text { Normalized } \\
\text { weights }\end{array}$ & Criteria & Weights & $\begin{array}{l}\text { Normalized } \\
\text { weights }\end{array}$ & \\
\hline \multirow{3}{*}{ Storage } & \multirow{3}{*}{0.3218} & \multirow{3}{*}{0.2576} & Storage capacity $(\mathrm{C} 1)$ & 0.1002 & 0.0963 & 0.0248 \\
\hline & & & Storage duration $(\mathrm{C} 2)$ & 0.2611 & 0.251 & 0.0647 \\
\hline & & & Storage hygiene (C3) & 0.6788 & 0.6527 & 0.1681 \\
\hline \multirow{2}{*}{ Processing } & \multirow{2}{*}{0.3900} & \multirow{2}{*}{0.3121} & Product quality (C4) & 0.7003 & 0.6948 & 0.2168 \\
\hline & & & Packaging quality (C5) & 0.3077 & 0.3052 & 0.0953 \\
\hline \multirow{2}{*}{ Sales } & \multirow{2}{*}{0.1839} & \multirow{2}{*}{0.1472} & Degree of efficiency (C6) & 0.3154 & 0.3129 & 0.0461 \\
\hline & & & Customer feedback (C7) & 0.6926 & 0.6871 & 0.1011 \\
\hline \multirow{2}{*}{ Transport } & \multirow{2}{*}{0.3537} & \multirow{2}{*}{0.2831} & Distance $(\mathrm{C} 8)$ & 0.5154 & 0.4818 & 0.1364 \\
\hline & & & Connectivity (C9) & 0.5543 & 0.5182 & 0.1467 \\
\hline
\end{tabular}

Table 5 Decision matrix: The aggregate fuzzy rating of 3 experts.

\begin{tabular}{|c|c|c|c|c|c|c|c|c|c|}
\hline & $\mathrm{C1}(+)$ & C2(-) & $\mathrm{C3}(+)$ & $\mathrm{C4}(+)$ & $\mathrm{C5}(+)$ & $\mathrm{C6}(+)$ & C7(+) & C8(-) & C9(+) \\
\hline A1 & {$[3,6.33,9]$} & {$[1,2.33,7]$} & {$[3,5,7]$} & {$[1,2.33,5]$} & {$[5,8.33,9]$} & {$[1,2.33,5]$} & {$[1,5,9]$} & {$[3,5.67,9]$} & {$[5,8.33,9]$} \\
\hline A2 & {$[1,3.67,7]$} & {$[3,5,7]$} & {$[7,9,9]$} & {$[1,2.33,7]$} & {$[1,3.67,7]$} & {$[1,1.67,5]$} & {$[1,2.33,7]$} & {$[3,5.67,9]$} & {$[5,7,9]$} \\
\hline A3 & {$[3,5.67,9]$} & {$[3,5.67,9]$} & {$[3,6.33,9]$} & {$[5,8.33,9]$} & {$[3,5,7]$} & {$[5,8.33,9]$} & {$[3,7.67,9]$} & {$[1,2.33,7]$} & {$[1,2.33,7]$} \\
\hline A4 & {$[1,3,7]$} & {$[1,4.33,7]$} & {$[1,2.33,5]$} & {$[3,5.67,9]$} & {$[3,5.67,9]$} & {$[1,5,9]$} & {$[3,5,7]$} & {$[1,3.67,7]$} & {$[3,5.67,9]$} \\
\hline A5 & {$[5,8.33,9]$} & {$[1,3.67,9]$} & {$[3,7,9]$} & {$[1,3.67,7]$} & {$[5,8.33,9]$} & {$[3,7,9]$} & {$[1,3.67,7]$} & {$[3,5,7]$} & {$[5,7,9]$} \\
\hline A6 & {$[3,5.67,9]$} & {$[1,1,3]$} & {$[1,2.33,5]$} & {$[1,4.33,7]$} & {$[3,6.33,9]$} & {$[3,5.67,9]$} & {$[3,7,9]$} & {$[1,1.67,5]$} & {$[1,4.33,7]$} \\
\hline A7 & {$[7,9,9]$} & {$[1,1.67,5]$} & {$[3,7,9]$} & {$[5,8.33,9]$} & {$[5,7.67,9]$} & {$[5,8.33,9]$} & {$[3,6.33,9]$} & {$[1,3,7]$} & {$[3,6.33,9]$} \\
\hline A8 & {$[3,5,7]$} & {$[1,2.33,5]$} & {$[3,6.33,9]$} & {$[3,5.67,9]$} & {$[1,3,5]$} & {$[1,4.33,7]$} & {$[3,6.33,9]$} & {$[3,5,7]$} & {$[1,3.67,7]$} \\
\hline A9 & {$[1,4.33,7]$} & {$[1,3,5]$} & {$[5,7,9]$} & {$[1,5,9]$} & {$[3,5.67,9]$} & {$[3,5.67,9]$} & {$[3,6.33,9]$} & {$[3,5,7]$} & {$[3,6.33,9]$} \\
\hline A10 & {$[3,5.67,9]$} & {$[1,2.33,7]$} & {$[3,5,7]$} & {$[5,8.33,9]$} & {$[1,4.33,7]$} & {$[3,5,7]$} & {$[5,7,9]$} & {$[1,3,7]$} & {$[1,4.33,7]$} \\
\hline A11 & {$[1,3,5]$} & {$[1,4.33,7]$} & {$[3,5.67,9]$} & {$[3,5,7]$} & {$[5,7,9]$} & {$[3,5.33,9]$} & {$[3,5,7]$} & {$[1,3,5]$} & {$[3,6.33,9]$} \\
\hline A12 & {$[1,4.33,9]$} & {$[5,7.67,9]$} & {$[1,3.67,7]$} & {$[1,3.67,7]$} & {$[1,3,5]$} & {$[1,1.67,5]$} & {$[1,2.33,7]$} & {$[5,7.67,9]$} & {$[1,3,7]$} \\
\hline A13 & {$[3,5.67,9]$} & {$[1,3,5]$} & {$[3,6.33,9]$} & {$[5,7,9]$} & {$[1,3.67,7]$} & {$[7,9,9]$} & {$[1,4.33,7]$} & {$[1,2.33,5]$} & {$[1,3.67,7]$} \\
\hline A14 & {$[1,3.67,7]$} & {$[1,2.33,5]$} & {$[3,5.67,9]$} & {$[3,6.33,9]$} & {$[3,5.67,9]$} & {$[1,3,5]$} & {$[5,7,9]$} & {$[1,4.33,7]$} & {$[3,5.67,9]$} \\
\hline A15 & {$[5,7.67,9]$} & {$[1,1.67,5]$} & {$[3,6.33,9]$} & {$[1,5,9]$} & {$[1,3.67,7]$} & {$[1,4.33,7]$} & {$[3,5.67,9]$} & {$[1,2.33,5]$} & {$[3,7,9]$} \\
\hline A16 & {$[5,7,9]$} & {$[1,1,3]$} & {$[3,5.67,9]$} & {$[3,5,7]$} & {$[1,3,5]$} & {$[1,4.33,7]$} & {$[1,1.67,5]$} & {$[3,5.67,9]$} & {$[3,5,7]$} \\
\hline A17 & {$[3,5.33,9]$} & {$[3,5,7]$} & {$[1,3.67,7]$} & {$[1,5,9]$} & {$[5,8.33,9]$} & {$[3,5,7]$} & {$[1,4.33,7]$} & {$[1,3,5]$} & {$[1,5,9]$} \\
\hline A18 & {$[1,4.33,9]$} & {$[3,7,9]$} & {$[1,2.33,7]$} & {$[3,5,7]$} & {$[1,3.67,7]$} & {$[1,3.67,7]$} & {$[1,3,5]$} & {$[3,6.33,9]$} & {$[1,3.67,7]$} \\
\hline
\end{tabular}




\begin{tabular}{cccccccccc}
\hline & $\mathbf{C 1}(+)$ & $\mathbf{C 2}(-)$ & $\mathbf{C 3}(+)$ & $\mathbf{C 4}(+)$ & $\mathbf{C 5}(+)$ & $\mathbf{C 6}(+)$ & $\mathbf{C 7}(+)$ & $\mathbf{C 8}(-)$ & $\mathbf{C 9}(+)$ \\
\hline $\mathbf{A 1 9}$ & {$[1,3,5]$} & {$[1,3,7]$} & {$[1,3.67,7]$} & {$[3,5.67,9]$} & {$[3,5.67,9]$} & {$[3,5.67,9]$} & {$[3,5,7]$} & {$[3,6.33,9]$} & {$[5,8.33,9]$} \\
$\mathbf{A 2 0}$ & {$[3,5,7]$} & {$[3,7,9]$} & {$[1,3,7]$} & {$[5,7,9]$} & {$[5,7,9]$} & {$[3,5.67,9]$} & {$[1,4.33,9]$} & {$[1,1.67,5]$} & {$[5,7.67,9]$} \\
$\mathbf{A 2 1}$ & {$[7,9,9]$} & {$[1,1,3]$} & {$[1,5,9]$} & {$[1,4.33,7]$} & {$[1,4.33,7]$} & {$[5,8.33,9]$} & {$[1,5,9]$} & {$[1,4.33,7]$} & {$[3,5.67,9]$} \\
$\mathbf{A 2 2}$ & {$[3,6.33,9]$} & {$[1,3.63,7]$} & {$[5,7,9]$} & {$[1,3,5]$} & {$[3,5,7]$} & {$[1,5,9]$} & {$[1,2.33,5]$} & {$[1,1.67,5]$} & {$[5,7.67,9]$} \\
$\mathbf{A 2 3}$ & {$[1,3,7]$} & {$[5,7,9]$} & {$[3,5.67,9]$} & {$[1,4.33,7]$} & {$[3,6.33,9]$} & {$[1,3,7]$} & {$[5,8.33,9]$} & {$[3,6.33,9]$} & {$[1,3.67,7]$} \\
$\mathbf{A 2 4}$ & {$[1,4.33,7]$} & {$[1,4.33,7]$} & {$[3,5.67,9]$} & {$[3,5,7]$} & {$[1,5,9]$} & {$[1,3.67,7]$} & {$[3,5,7]$} & {$[1,3,5]$} & {$[1,4.33,7]$} \\
\hline
\end{tabular}

Table 6 Closeness coefficient, ranking, and classification.

\begin{tabular}{cccccc}
\hline Supermarkets & $\boldsymbol{E}^{+}$ & $\boldsymbol{E}^{-}$ & $\boldsymbol{C} \boldsymbol{C}=\frac{\boldsymbol{E}^{-}}{\boldsymbol{E}^{+}+\boldsymbol{E}^{-}}$ & Rank & Class \\
\hline $\mathbf{A 1}$ & 0.3349 & 0.2475 & 0.4250 & 19 & $\mathrm{~B}$ \\
$\mathbf{A 2}$ & 0.3502 & 0.2414 & 0.4080 & 20 & $\mathrm{~B}$ \\
$\mathbf{A 3}$ & 0.2317 & 0.3558 & 0.6056 & 3 & $\mathrm{~A}$ \\
$\mathbf{A 4}$ & 0.3231 & 0.2917 & 0.4745 & 16 & $\mathrm{~B}$ \\
$\mathbf{A 5}$ & 0.2988 & 0.3053 & 0.5054 & 12 & $\mathrm{~B}$ \\
$\mathbf{A 6}$ & 0.3024 & 0.2816 & 0.4822 & 14 & $\mathrm{~B}$ \\
$\mathbf{A 7}$ & 0.1406 & 0.4578 & 0.7650 & 1 & $\mathrm{~A}$ \\
$\mathbf{A 8}$ & 0.3408 & 0.2564 & 0.4293 & 18 & $\mathrm{~B}$ \\
$\mathbf{A 9}$ & 0.2828 & 0.3305 & 0.5389 & 9 & $\mathrm{~B}$ \\
$\mathbf{A 1 0}$ & 0.2363 & 0.3587 & 0.6028 & 4 & $\mathrm{~A}$ \\
$\mathbf{A 1 1}$ & 0.2615 & 0.3437 & 0.5679 & 8 & $\mathrm{~A}$ \\
$\mathbf{A 1 2}$ & 0.5013 & 0.0861 & 0.1466 & 24 & $\mathrm{C}$ \\
$\mathbf{A 1 3}$ & 0.2566 & 0.3511 & 0.5778 & 6 & $\mathrm{~A}$ \\
$\mathbf{A 1 4}$ & 0.2478 & 0.3700 & 0.5989 & 5 & $\mathrm{~A}$ \\
$\mathbf{A 1 5}$ & 0.2641 & 0.3587 & 0.5759 & 7 & $\mathrm{~A}$ \\
$\mathbf{A 1 6}$ & 0.3525 & 0.2226 & 0.3870 & 21 & $\mathrm{~B}$ \\
$\mathbf{A 1 7}$ & 0.3363 & 0.2854 & 0.4590 & 17 & $\mathrm{~B}$ \\
$\mathbf{A 1 8}$ & 0.4518 & 0.1406 & 0.2373 & 23 & $\mathrm{C}$ \\
$\mathbf{A 1 9}$ & 0.3037 & 0.2935 & 0.4915 & 13 & $\mathrm{~B}$ \\
$\mathbf{A 2 0}$ & 0.2299 & 0.3654 & 0.6138 & 2 & $\mathrm{~A}$ \\
$\mathbf{A 2 1}$ & 0.2985 & 0.3300 & 0.5250 & 10 & $\mathrm{~B}$ \\
$\mathbf{A 2 2}$ & 0.2820 & 0.3074 & 0.5216 & 11 & $\mathrm{~B}$ \\
$\mathbf{A 2 3}$ & 0.3652 & 0.2244 & 0.3806 & 22 & $\mathrm{~B}$ \\
$\mathbf{A 2 4}$ & 0.3210 & 0.2965 & 0.4802 & 15 & $\mathrm{~B}$ \\
\hline
\end{tabular}

Sensitivity analysis $[31,32]$ is one kind of experiment, which tests the robustness and the stability of the decision. It generates some conditions and tests the behavior of the system. The weights from fuzzy AHP are interchanged between the criteria to generate virtual conditions. Then, fuzzy TOPSIS will be applied for each of the conditions to check the stability of the decision. If there is $n$ number of criteria then we can generate $C_{2}^{n}$ combination by exchanging the weights between 2 criteria at a time. In this work, we have 9 criteria. Hence, 36 combinations are generated from there by exchanging weights between 2 criteria at a time. Each combination will act as a specific condition. Figure 4 shows the graphical plot of the closeness coefficient value in 36 conditions for each alternative store. In this plot, the $0^{\text {th }}$ combination shows the result of this case study. The rests are the results of the virtual conditions that are generated for sensitivity analysis. The plot conveys that the fruits and vegetable store in the $7^{\text {th }}$ supermarket (A7) is the best. The store for fruits and vegetables in the $12^{\text {th }}$ supermarket (A12) is the worst for all the combinations of weights. 


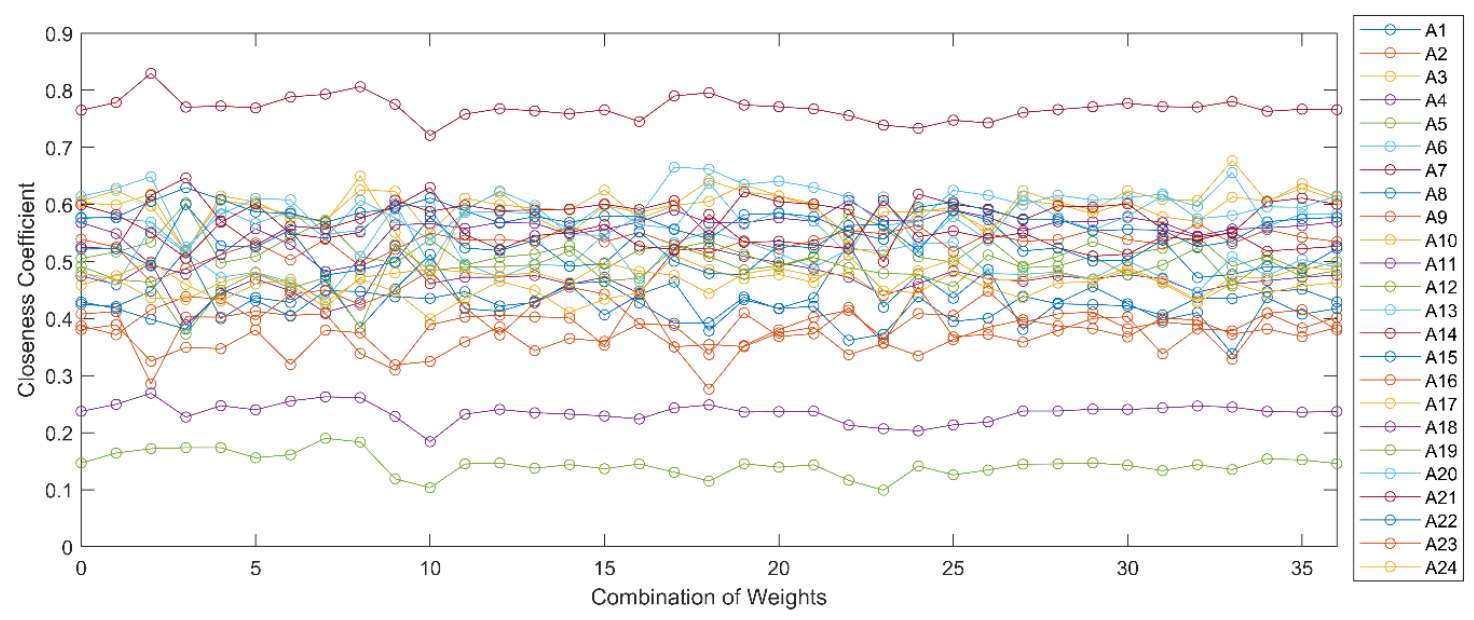

Figure 4 Variation of closeness coefficient for the different combination of weights in the sensitivity analysis.

Root Mean Square Error (RMSE) [33] measures the errors of result from the standard value. Generally, it is used to see the accuracy of the result. The deviation of closeness coefficient values of 36 conditions from the closeness coefficient values of the base condition is measured for all the alternatives using equation (30). ' $c c$ ' is the closeness coefficient value for base condition and ' $c c_{i}$ ' is the closeness coefficient value for $i^{t h}$ condition. ' $t$ ' represents the total number of conditions. Here the value of $t$ is 36 . Figure 5 shows the RMSE for each of the alternative stores in the sensitivity analysis. This depicts the correctness of decisions made by the fuzzy TOPSIS technique.

$R M S E=\sqrt{\frac{\sum_{i=1}^{t}\left(c c-c c_{i}\right)^{2}}{t}}$

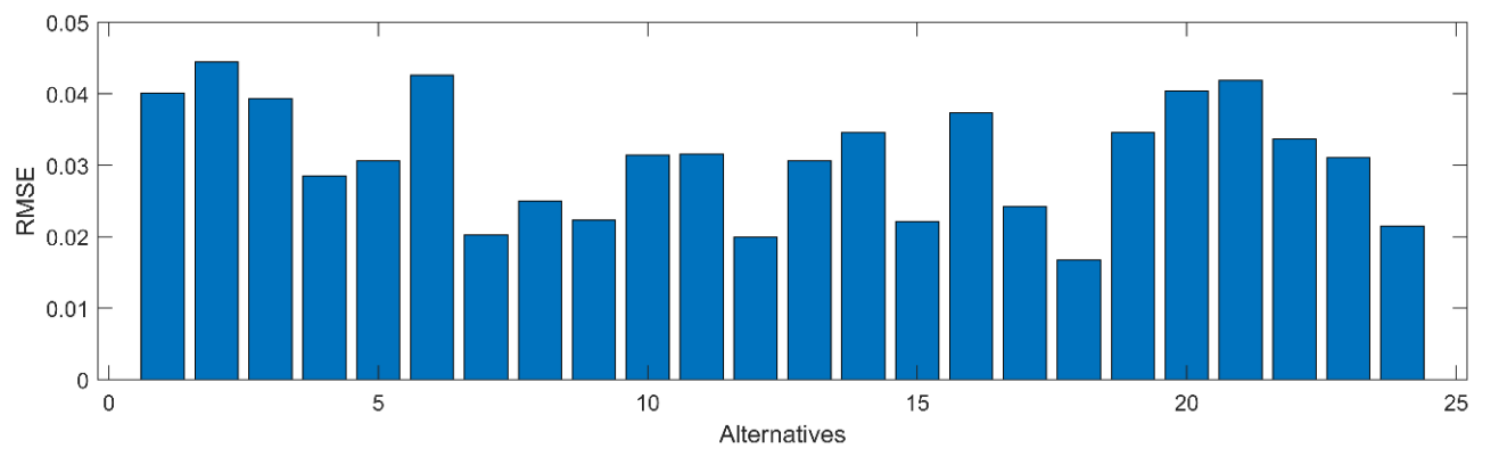

Figure 5 RMSE for different alternatives in the sensitivity analysis.

\section{Conclusions}

The previous approaches for performance evaluation mostly did the ranking of alternatives using various MCDM techniques. It can be said based on our literature survey that this is the first attempt for performance evaluation of fruits and vegetable stores. This paper proposes an integrated framework for the performance evaluation of fruits and vegetable stores located in supermarkets. The main contribution of this paper is that the proposed framework not only ranks the alternative fruits and vegetable stores but also does a classification among the alternative fruits and vegetable stores based on their performance. This framework helps the management of the supermarket to identify their flaws and areas of improvement for the fruits and vegetable stores. This framework also guides the customers to decide the 
best store for buying fresh fruits and vegetables. The criteria and the alternatives for performance evaluation need to be identified first. Then it takes the input of relative importance from the expert's committee and calculates the weights for each criterion using fuzzy AHP. The fuzzy decision matrix is prepared with the alternatives, criteria, and inputs from the expert's committee. The fuzzy weighted normalized decision matrix is generated by multiplying weights from fuzzy AHP with the fuzzy normalized decision matrix. The alternatives are ranked and classified based on the closeness coefficient by applying fuzzy $k$-TOPSIS on a fuzzy weighted normalized decision matrix. The sensitivity analysis of results is done to verify the dependence of alternatives on weights. The sensitivity analysis result assures that the use of this framework leads to a stable and robust decision. This framework could be used in many other decision-making problems. The future scope should be the inclusion of other criteria that might affect the performance of fruits and vegetable stores.

\section{References}

[1] AH Maslow. A theory of human motivation. Psychol. Rev. 1943; 50, 370-96.

[2] JA Pennington and RA Fisher. Classification of fruits and vegetables. J. Food Compos. Anal. 2009; 22, S23-S31.

[3] S Strom. Weak links in China's food chain. New York Times, Available at: http://www.nytimes.com/2014/08/01/business/international/weak-links-inchinas-foodchain.html?_r=0, accessed February 2019.

[4] A Saba, E Moneta, M Peparaio, F Sinesio, M Vassallo and F Paoletti. Towards a multi-dimensional concept of vegetable freshness from the consumer's perspective. Food Qual. Preference 2018; 66, $1-12$.

[5] Y Wang, W Ji and SS Chaudhry. A hybrid approach for the evaluation of supermarket food safety. J. Manag. Analytics 2014; 1, 156-67.

[6] GM Duman, O Tozanli, E Kongar and SM Gupta. A holistic approach for performance evaluation using quantitative and qualitative data: A food industry case study. Expert syst. Appl. 2017; 81, 41022.

[7] RD Raut, BB Gardas, M Kharat and B Narkhede. Modeling the drivers of post-harvest lossesMCDM approach. Comput. Electron. Agr. 2018; 154, 426-33.

[8] RD Raut, BB Gardas, VS Narwane and BE Narkhede. Improvement in the food losses in fruits and vegetable supply chain-a perspective of cold third-party logistics approach. Oper. Res. Perspect. $2019 ; 6,100117$.

[9] TL Saaty. Decision making with the analytic hierarchy process. Int. J. Serv. Sci. 2008; 1, 83-98.

[10] YJ Lai, TY Liu and CL Hwang. Topsis for MODM. Eur. J. Oper. Res. 1994; 76, 486-500.

[11] EK Zavadskas, Z Turskis, J Tamosaitiene and V Marina. Selection of construction project managers by applying COPRAS-G method. Comput. Model. New Tech. 2008; 12, 22-8.

[12] P Karande and S Chakraborty. Application of multi-objective optimization on the basis of ratio analysis (MOORA) method for materials selection. Mater. Des. 2012; 37, 317-24.

[13] A Azimifard, SH Moosavirad and S Ariafar. Selecting sustainable supplier countries for Iran's steel industry at three levels by using AHP and TOPSIS methods. Resources Pol. 2018; 57, 30-44.

[14] M Ligus and P Peternek. Determination of most suitable low-emission energy technologies development in Poland using integrated fuzzy AHP-TOPSIS method. Energ. Proc. 2018; 153, 1016.

[15] MC Hsieh, EMY Wang, WC Lee, LW Li, CY Hsieh, W Tsai and TC Liu. Application of HFACS, fuzzy TOPSIS, and AHP for identifying important human error factors in emergency departments in Taiwan. Int. J. Ind. Ergon. 2018; 67, 171-9.

[16] A Khoshi, HS Gooshki and N Mahmoudi. The data on the effective qualifications of teachers in medical sciences: An application of combined fuzzy AHP and fuzzy TOPSIS methods. Data Brief 2018; 21, 2689-93.

[17] K Mandic, B Delibasic, S Knezevic and S Benkovic. Analysis of the financial parameters of Serbian banks through the application of the fuzzy AHP and TOPSIS methods. Econ. Model. 2014; 43, 307.

[18] RP Kusumawardani and M Agintiara. Application of fuzzy AHP-TOPSIS method for decision making in human resource manager selection process. Proc. Comput. Sci. 2015; 72, 638-46.

[19] O Taylan, AO Bafail, RM Abdulaal and MR Kabli. Construction projects selection and risk assessment by fuzzy AHP and fuzzy TOPSIS methodologies. Appl. Soft Comput. 2014; 17, 105-16. 
[20] H Karahalios. The application of the AHP-TOPSIS for evaluating ballast water treatment systems by ship operators. Transport. Res. Transport. Environ. 2017; 52, 172-84.

[21] J Wang, K Fan and W Wang. Integration of fuzzy AHP and FPP with TOPSIS methodology for aeroengine health assessment. Expert Syst. Appl. 2010; 37, 8516-26.

[22] LA Zadeh. Fuzzy sets. Inform. Contr. 1965; 8, 338-53.

[23] TL Saaty. What is the analytic hierarchy process? In: G Mitra, HJ Greenberg, FA Lootsma, MJ Rijkaert and HJ Zimmermann (Eds.). Mathematical models for decision support. Springer, Berlin, Heidelberg, 1988, p. 109-121.

[24] JJ Buckley. Fuzzy hierarchical analysis. Fuzzy Set. Syst. 1985; 17, 233-47.

[25] A Yazdani-Chamzini and SH Yakhchali. Tunnel Boring Machine (TBM) selection using fuzzy multifactors decision making methods. Tunnelling and Underground Space Tech. 2012; 30, 194204.

[26] CL Hwang and K Yoon. Methods for multiple attribute decision making. In: CL Hwang and K Yoon (Eds.). multiple attribute decision making. lecture notes in economics and mathematical systems. Vol 186. Springer, Berlin, Heidelberg, 1981, p. 58-191.

[27] K Yoon. A reconciliation among discrete compromise solutions. J. Oper. Res. Soc. 1987; 38, $277-$ 86.

[28] S Nădăban, S Dzitac and I Dzitac. Fuzzy topsis: A general view. Proc. Comput. Sci. 2016; 91, 82331.

[29] J MacQueen. Some methods for classification and analysis of multivariate observations. In: Proceedings of the $5^{\text {th }}$ Berkeley Symposium on Mathematical Statistics and Probability. California. 1967, p. 281-97.

[30] H Steinhaus. Sur la division des corpmateriels en parties. Bull. Acad. Polon. Sci. 1956; 4, 801-4.

[31] S Dewangan, S Gangopadhyay and CK Biswas. Study of surface integrity and dimensional accuracy in EDM using Fuzzy TOPSIS and sensitivity analysis. Measurement 2015; 63, 364-76.

[32] R Simanavičienė and V Petraitytè. Sensitivity Analysis of the TOPSIS method in respect of initial data distributions. Lithuanian J. Stat. 2016; 55, 45-51.

[33] T Chai and RR Draxler. Root mean square error (RMSE) or mean absolute error (MAE)? Arguments against avoiding RMSE in the literature. Geosci. Model Deve. 2014; 7, 1247-50. 